\section{REFERENCES}

1. NSW Department of Health. NSW Tobacco Action Plan 20012004. Sydney: NSW Department of Health, 2001.

2. Department of Health and Aging. National Tobacco Strategy 1999-2003: A Framework for National Action. Canberra: AGPS, 1999.

3. Irish Department of Health at www.doh.ie/publications/ smokeban accessed January 2004.

4. New Zealand Ministry of Health at www.ndp.govt.nz/tobacco/ tobacco01 accessed January 2004.

5. Ministerial Statement, the Hon. Frank Sartor, Minister Assisting the Minister of Health (Cancer), NSW Legislative Assembly, 19 October 2004.

6. Tzelepis F, Walsh R, Paul C. Community attitudes towards environmental tobacco smoke in licenced premises:followup study after the Sharp case. Aust N Z J Public Health 2003; 27(5): 539-542.
7. Newspoll report commissioned by NSW Department of Health. Community attitudes to Smoking bans. Sydney: Newspoll, 2004 (unpublished).

8. Eureka Research report commissioned by NSW Department of Health. NSW Campaign regarding young children's exposure to environmental tobacco smoke in homes and cars Evaluation Survey (Wave 1) Sydney: Eureka Research, 2003 (unpublished).

9. Tobacco and Health Branch, Centre for Chronic Disease Prevention and Health Advancement. 2003-2004 Tobacco legislation compliance rates. Sydney: NSW Department of Health, 2004 (unpublished).

10. NSW Department of Health. Guide for the management of nicotine dependent inpatients. Sydney: NSW Department of Health, 2002.

11. New South Wales Adult Health Survey 2002 (HOIST). Centre for Epidemiology and Research, NSW Department of Health. W

\title{
MANAGING NICOTINE DEPENDENCE IN NSW HOSPITAL PATIENTS
}

\author{
Luke Wolfenden, Megan Freund, Elizabeth Campbell, \\ and John Wiggers \\ Hunter Centre for Health Advancement \\ Hunter Area Health Service

\section{Christine Paul} \\ Centre for Health Research and Psycho-oncology \\ The Cancer Council New South Wales
}

\section{Elayne Mitchell}

Tobacco and Health Branch,

NSW Department of Health

\section{BACKGROUND}

In recognition of the adverse consequences of tobacco use on patient health, ${ }^{1}$ the financial burden of smoking on the health care system, ${ }^{2}$ and the role of health services in the treatment of tobacco users (to enable their cessation of smoking), the NSW Department of Health has implemented a number of smoking cessation initiatives in recent years. Among these are the 1999 NSW Smokefree Workplace Policy, which requires all area health service facilities and campuses to become smoke-free, ${ }^{3}$ and the development and release of the Guide for the Management of Nicotine Dependent Inpatients in 2002. ${ }^{4}$ This article describes the implications of the NSW Smokefree Workplace Policy on hospitals and discusses the development and utility of the Guide in the context of the ongoing challenge of improving care for inpatients who are dependent on nicotine.

\section{THE PROVISION OF SUPPORT TO SMOKERS BY HOSPITAL STAFF}

There is little research in Australia that has investigated tobacco use by patients during their hospitalisation and the support provided by hospital staff to assist patients to abstain from smoking. Evidence suggests that while approximately 20-35 per cent of hospital patients are smokers, ${ }^{5,6}$ the provision of support for smokers within Australian hospitals is limited. A small cohort study by Feeney et al. of 60 inpatients who were smokers from medical or surgical wards found that 20 per cent of these patients reported that they had been offered assistance with quitting tobacco smoking by medical staff. ${ }^{7}$ Further, a larger study of over 300 direct care nurses from six hospitals in NSW indicated that while the majority of staff felt that providing smoking cessation advice and assistance to patients was part of their clinical role, they lacked knowledge of effective cessation strategies. ${ }^{8}$ The study found that only 21 per cent of staff felt competent to discuss cessation with patients. Following the introduction of the NSW Smoke-free Workplace Policy, the only published research evaluating tobacco use and the provision of smoking cessation support within NSW hospitals is a study by Boomer and Rissel. ${ }^{9}$ This study recruited self-reported smokers during attendance at preadmission clinics at two large hospitals within the Central Sydney Area Health Service. Sixty-eight smokers were followed up after discharge. Reported assistance with smoking abstinence ranged from 17-38 per cent between 
hospitals. While 19 per cent reported smoking while they were hospitalised, none of the 68 patients were offered Nicotine Replacement Therapy during their hospital stay.

\section{GUIDE FORTHE MANAGEMENT OF NICOTINE DEPENDENT INPATIENTS}

\section{Development}

Clinical guidelines have been found to be an important step in changing clinical practice, ${ }^{10}$ and are appropriate to assist with the delivery of smoking cessation advice to patients. Within the context of the NSW Smoke-free Workplace Policy, NSW Health developed the Guide for the Management of Nicotine Dependent Inpatients. ${ }^{4}$ The Guide synthesised the literature describing best practice into a practical, evidence-based framework to enable hospital-based health professionals to manage inpatient nicotine dependence and to encourage permanent smoking cessation. Table 1 outlines the strategies employed during the development of the Guide to enhance local ownership, ensure that the Guide was professionally credible, and to facilitate its implementation. These strategies have been found to be effective, ${ }^{11}$ and are similar to those used during the development of other international 'best practice' guidelines. ${ }^{12,13}$ The Guide was officially launched and disseminated to the chief executive officers of the area health services in 2002.

\section{Recommendations}

A summary of the recommended steps in the management of nicotine dependent patients is presented in Table 2 . The Guide specifies that patients who smoke are identified, informed of the Smoke-free Workplace Policy, and advised of their options for managing their nicotine withdrawal during their stay in hospital. ${ }^{4}$ The primary strategy presented to manage nicotine dependence is through the prescription of Nicotine Replacement Therapy. Nicotine Replacement Therapy relieves the withdrawal symptoms associated with cessation, ${ }^{14}$ and has been consistently found to double the long-term quit rates of patients. ${ }^{12,15}$ Patients who are able to abstain from smoking and do not experience withdrawal symptoms during their hospital stay are known to be more likely to remain abstinent after discharge,${ }^{16}$ emphasising the

\section{TABLE 1}

STRATEGIES EMPLOYED DURING THE DEVELOPMENT OF THE GUIDE FOR THE MANAGEMENT OF NICOTINE DEPENDENT INPATIENTS

- Formation of a 10 member advisory group with expert representation from various relevant health department disciplines and non-government organisations.

- Review of existing scientific literature and clinical practice guidelines.

- Qualitative research with two area health services.

- Dissemination of preliminary versions of the Guide to experts, professional bodies and each area health service for comment, support and endorsement.

- Revise Guide content in response to feedback.

Source: Tobacco and Health Branch, NSW Department of Health.

\section{TABLE 2}

\section{RECOMMENDED STEPS IN THE MANAGEMENT OF NICOTINE DEPENDENT INPATIENTS}

Recommended steps Recommended actions

1. Identify tobacco users on admission

- Ex-smokers: Encourage continued abstinence

2. Manage inpatient nicotine withdrawal

- Daily or occasional smokers: Follow steps 2-9.

- Inform patient of the NSW Health Smoke-free Workplace Policy

- Specify treatment contraindications if they leave the ward-facility to smoke

- Discuss options for the management of nicotine dependence: abstinence; abstinence plus Nicotine Replacement Therapy if not contraindicated; smoking offsite or in a designated area.

3. Prescribe Nicotine Replacement Therapy

- Arrange prescription of Nicotine Replacement Therapy

- Record: Nicotine Replacement Therapy type and dose on medications chart; 'nicotine dependent' in patient notes.

4. Monitor patient withdrawal symptoms

- Review Nicotine Replacement Therapy dose and/or product if patient experiences withdrawal symptoms.

5. Discharge

- Encourage future quit attempt for patients who plan to resume smoking after discharge

- For patients who do not plan to smoke after discharge: arrange three-day post discharge NRT; include treatment summary in discharge plan; advise patient seek support from general practitioner or pharmacist or Quitline.

Source: Guide for the management of nicotine dependent patients. Sydney: NSW Department of Health, $2002 .{ }^{4}$ 
importance of successful inpatient management. In recognition of the potential for relapse during the post discharge period, ${ }^{17,18}$ for patients interested in quitting, the Guide recommends that hospital staff provide patients with: a three-day supply of Nicotine Replacement Therapy; encourage the patient to seek support after their discharge; and inlcude a summary of their treatment in the discharge plan. ${ }^{4}$

\section{Benefits of implementation}

The implementation of the Guide has a number of potential benefits for hospitals. Successful treatment of nicotine withdrawal will reduce the need for hospitalised smokers to leave the site to smoke when a facility or campus is completely smoke-free. The provision of treatment for nicotine dependence as detailed in the Guide can also be expected to contribute to reductions in the prevalence of tobacco use among the population and, potentially, reductions in the utilisation of health services. ${ }^{2,12}$ The provision of smoking cessation interventions is costeffective and the net benefit-cost ratio of programs to reduce tobacco consumption is estimated to be $50: 1 .^{27}$ Patients who quit smoking have improved immune functioning, a reduced risk of complications, and are less likely to be re-admitted. ${ }^{6,19,20}$ Finally, implementation of the Guide in hospitals will provide a healthier environment for staff, patients, and visitors, and delivers a clear message to the community regarding the health consequences of smoking.

\section{Challenges for improving treatment of nicotine dependence in NSW hospitals}

Despite the dissemination of the Guide, hospitals are likely to face ongoing challenges in improving the care offered to nicotine dependent patients. ${ }^{21}$ Change in clinical practice is best achieved through the use of strategies that are tailored to overcome barriers within the local setting. ${ }^{22}$ Consequently, while providing specific recommen-dations, the Guide is generic and encourages local adaptation. Recent reviews of the literature also suggest that achieving effective clinical practice will require the use of a combination of strategies including staff training, environmental supports such as prompts or reminders and performance targets, and feedback. ${ }^{23,24,25}$ Hospital-wide improvements to the management of nicotine dependence should also have high level support and endorsement and must be institutionalised in order to be sustainable. ${ }^{12,26}$

Currently in NSW, area health services implement smoking cessation strategies from within existing resources. To facilitate the Guide's implementation, the NSW Department of Health has funded, through its Health Promotion Demonstration Research Scheme, a project that will evaluate the success of an intervention to encourage adoption of the recommendations in the Guide by two hospitals, one each in the Hunter and Mid West Area Health
Services. The NSW Department of Health will also provide area health services with ongoing support to enhance delivery of smoking cessation within the NSW health system. Recently-developed national competency standards for population health include two elective units of competency in evidence-based best practice in the delivery of smoking cessation. In 2004, the Tobacco and Health Branch will work with area health services and Quitline staff to develop a program of training and accreditation for health professionals in nicotine dependence and smoking cessation. The training will be delivered through a combination of face-to-face training courses; online resources; and training materials including a handbook, video, and fact sheets.

Given the limited available evidence, a need has been established for more comprehensive research into the management of nicotine dependent patients in NSW and Australian hospitals. At the time of the release of the Guide, a large cross-sectional survey was undertaken of senior managers from publicly-funded NSW hospitals with inpatient facilities. The survey required managers to report, via questionnaire, current practices within their hospital that support the appropriate management of inpatients who are smokers. Results from the study are currently being finalised and are expected to be available in 2004. In addition to the survey, a follow-up statewide survey is being considered to assess compliance with the Guide by hospitals.

\section{CONCLUSION}

While change in clinical practice is difficult to achieve, particularly within the hospital setting, the Guide for the Management of Nicotine Dependent Inpatients is a valuable and practical resource for hospitals in the management of tobacco users in a smoke-free environment. Successful implementation of the Guide will not only reduce the distress of inpatients who are smokers but is likely to contribute to population health outcomes through long-term smoking cessation.

\section{REFERENCES}

1. United States Department of Health and Human Services. The Health Benefits of Smoking Cessation. A report of the Surgeon-General. Rockville, Maryland: United States Department of Health and Human Services, Centers for Disease Control, Center for Chronic Disease Prevention and Health Promotion, Office on Smoking and Health, 1990.

2. Collins DJ and Lapsley HM. Counting the costs: Estimates of the social costs of drug abuse in Australia 1998-99. Canberra: Commonwealth Department of Health and Ageing, 2002.

3. Public Health Division. Smoke Free Workplace Policy. Sydney: NSW Department of Health, 1999.

4. NSW Department of Health. Guide for the management of nicotine dependent inpatients. Sydney: NSW Department of Health, 2002. 
5. Schofield PE, Hill DJ. How accurate is in-patient smoking status data collected by hospital admissions staff? Aust N Z J Public Health 1999; 23(6): 654-656.

6. Bittoun R, McMahon M, Bryant DH. Smoking in hospitalised patients. Addict Behav 1991; 16: 79-81.

7. Feeney GFX, Kelly A, Griffin DK, Young RMD. Smoking interventions within the hospital setting: A study of demand for smoking interventions and perceived efficacy of nurses in delivery of services. Health Promotion Journal of Australia 1997; 7(1): 52-55.

8. Nagle A, Schofield M, Redman, S. Australian nurses smoking behaviour, knowledge and attitude towards providing smoking cessation care to their patients. Health Promot Int 1999; 14(2): 133-144.

9. Boomer MJ and Rissel C. An evaluation of a smoke free environment policy in two Sydney hospitals. Australian Health Review 2002; 25(3): 179-84.

10. Davis DA and Taylor-Vaisey A. Translating guidelines into practice: A systematic review of theoretic concepts, practical experience and research evidence in the adoption of clinical practice guidelines. Can Med Assoc J 1997; 157(4): 408-416.

11. Thomson R, Lavender M, Madhok R. How to ensure guidelines are effective. BMJ 1995; 311(6999): 237-243.

12. Fiore MC, Bailey WC, Cohen SJ et al. Treating Tobacco Use and Dependence: Clinical Practice Guideline. Rockville, Maryland: United States Department of Health and Human Services, Public Health Service, 2000.

13. Raw M, McNeill A, West R. Smoking cessation guidelines for health professionals: A guide to effective smoking cessation interventions for the health care system. The Journal of the British Thoracic Society 1998; 53(S-5): s3-s7.

14. Copeland AL, Brandon TH. Intervening with the tobaccodependent patient. Journal of Clinical Outcomes Management 2001; 8(6): 43-51.

15. Silagy C, Lancaster T, Stead L, Mant D, Fowler G. Nicotine replacement therapy for smoking cessation (Cochrane Review). Cochrane Library, Issue 4, 2003. Chichester, UK: John Wiley and Sons Ltd, 2003.

16. Sciamanna CN, Stillman FA, Hoch JS, Butler JH, Gass KG, Ford DE. Opportunities for improving inpatient smoking cessation programs: A community hospital experience. Prev Med 2000; 30: 496-503.
17. Griebel B, Wewers ME, Baker CA. The effectiveness of a nurse-managed minimal smoking-cessation intervention among hospitalized patients with cancer. Oncol Nurs Forum 1998; 25(5): 897-902.

18. Rigotti NA, McKool KM, Shiffman S. Predictors of smoking cessation after coronary artery bypass graft surgery: Results of a randomized trial with 5-year follow-up. Ann Intern Med 1994; 120(4): 287-293.

19. The Australian and New Zealand College of Anaesthetists. Statement on smoking as related to the perioperative period. Available online at www.medeserv.com.au/anzca/ publications/profdocs/profstandards/ps12_2001.htm.

20. Moller AM, Villebro N, Pedersen T, Tonnesen H. Effects of pre-operative smoking intervention on post-operative complications: A randomised clinical trial. Lancet 2002; 359: 114-119.

21. Stanton WR, Balanda KP, Gillespie AM, Lowe JB. Barriers to health promotion activities in public hospitals. Aust NZJ Public Health 1996; 20(5): 500-504.

22. Moulding NT, Silagy CA, Weller DP. A framework for effective management of change in clinical practice: dissemination and implementation of clinical practice guidelines. Quality in Health Care 1999; 8: 177-183.

23. Hulscher MEJL, Wensing M, van der Weijden T, Grol R. Interventions to implement prevention in primary care (Cochrane Review). Cochrane Library, Issue 4, 2003. Chichester, UK: John Wiley and Sons Ltd, 2003.

24. Bero LA, Grilli R, Grimshaw JM, Harvey E, Oxman AD, Thomson MA. Closing the gap between research and practice: An overview of systematic reviews of interventions to promote the implementation of research findings. BMJ 1998; 317: 465468.

25. Oxman AD, Thomson MA, Davis DA, Haynes BR. No magic bullets: A systematic review of 102 trials of interventions to improve professional practice. Can Med Assoc J 1995; 153(10): 1423-1431.

26. Curry SJ. Organizational Interventions to Encourage Guideline Implementation. Chest 2000; 118: s40-s46.

27. Abelson P. Returns on Investment in Public Health: An epidemiological and economic analysis prepared for the Department of Health and Ageing. Canberra: Commonwealth Department of Health and Ageing, 2003. 